\title{
Administração de justiça e construção de hegemonia
}

\section{Administration of lustice and construction of hegemony}

\section{esumo}

Este artigo apresenta uma reflexão sobre a participação da Administração de Justiça nos processos de formação e expansão da cultura jurídica. Nesse sentido, e tendo como pressuposto que os juízes expandem a cultura jurídica através das suas práticas judiciais, afirmase que somente uma reforma intelectual e moral, no sentido gramsciano do conceito, que compreenda a todas as pessoas (incluindo os operadores de direito) possui a capacidade de produzir uma transformação radicalmente democrática dessa mesma cultura. Afirma-se também que muitas possibilidades, no caminho assinalado, abrem-se a partir do núcleo de bom senso presente no senso comum jurídico. Ainda assim torna-se indispensável a democratização interna do Judiciário e o controle externo das suas atividades jurisdicionais.

Palavras-chave: Poder Judiciário, administração de justiça, democracia plural e radical.

\section{Astract}

This article offers a reflection on the participation of the Administration of Justice in the processes of formation and expansion of legal culture. In this sense, and based on the supposition that judges expand the legal culture through their judicial practices, it affirms that only an intellectual and moral reform, in the Gramscian sense of the concept, which comprehends all the people (including the operators of law) can produce a radically democratic transformation of this culture. It also maintains that many possibilities for the route indicated open from good, common legal sense, but also become indispensable to the internal democratization of the Judiciary and the external control of its jurisdictional activities.

\section{María del Carmen Cortizo}

Key words: Judicial Power, administration of justice, plural and radical democracy.
Doutora em Ciências Sociais pela Universidade Estadual de Campinas UNICAMP - SP.

Professora do Dep. de Serviço Social da UFSC. 
... Nei momenti de crisi [...] i popoli possono forse smarrire il senso dellalegalità, non perdono il senso della giustizia. Come senso della giustizia intendiamo non qualcosa d'inaferrabile e aereo, $m a$, concretamente, il deposito di un'esperienza vissuta di secoli o di

mileni, che nei grandi sconvolgimenti della storia ritorna alla luce come le fondaments di un edificio crollato. Esperienza storica, dunque.

Francesco Calasso

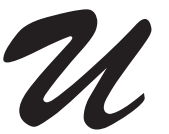

ma das faces da administração de justiça realizada pelo Judiciário é a sua capacidade de difundir certas práticas, vinculadas a determinados valores sociais, ou seja, de expandir cultura jurídica.

Entendemos por cultura jurídica - compreendida dentro do âmbito mais amplo da cultura política-aquele processo social de conformação das orientações axiológicas e práticas diante do direito, - do que é efetivamente e do que deve vir a ser. Enquanto processo dinâmico de constituição de valores e práticas, a cultura jurídica é cenário de lutas pela direção desse processo.

$\mathrm{O}$ conceito de cultura jurídica, aqui apresentado enquanto categoria analítica, permite pensar a realidade da interação entre Judiciário e cidadania e, também, construir projetos de transformação que aceitem a possibilidade de formas institucionais democratizadoras alternativas $^{1}$ dentro da administração de justiça, surgidas da realidade concreta da sociedade em conjunção com o Poder Judiciário. A finalidade dessas formas, para além de realizar a justiça como valor histórico, é democratizar a sociedade e o Judiciário, que é um espaço tipicamente não democrático da organização da administração pública do Estado. Mas, como assinala Nun (2000, p. 174):

Esto exige que la lucha contra la desigualdad sea asumida como primordial y que inventemos entre todos nuevas formas institucionales que complementen, transformen y amplien las existentes, pues de lo contrario la experiencia enseña que éstas son un plano inclinado que lleva al mantenimiento del 'statu quo' o a algo peor.

Reitero que elaborar un catálogo de esas formas sería un ejercicio tan fácil como inútil puesto que, por definición, deben respetar las diferencias y poseer rasgos propios según las características de cada lugar. Alcanza con saber que son posibles; que ya hay muchas que están en pie y deben ser profundizadas, articuladas y difundidas; y que sería bueno que los intelectuales latinoamericanos que todavía no lo han hecho aceptasen como una de sus misiones más significativas la de interpretar, fortalecer, traducir y comunicar esas experiencias.

As pessoas passam a ter noção do que seja o direito a partir da maneira como os seus direitos são efetivamente conhecidos e exercidos. O titular de um direito tem a percepção de que pode exercer esse direito plenamente se houver para ele, diante da violação ou da não efetivação de um direito formalmente declarado em lei, a possibilidade real de obter uma reparação ou efetivação, mediante a intervenção dos órgãos pertinentes da administração de justiça do Estado.

Nessa percepção empírica do funcionamento efetivo dos direitos as pessoas constroem a própria concepção do mundo jurídico, que integra o senso comum que todo sujeito possui. Imprimem, portanto, uma dinâmica própria aos processos de transformação social dos quais participam, seja no que diz respeito aos fins que se pretende atingir, seja quanto aos meios considerados adequados para alcançar tais fins, já que as concepções de mundo são parte e fundamento das práticas sociais.

Os juízes realizam a expansão da cultura jurídica fundamentalmente - e de modo quase exclusivo - através das suas práticas no processo judiciário, já que apenas em raras ocasiões - embora cada vez com maior freqüência - manifestem-se publicamente por outros meios. Não resulta possível pensar em uma reformulação da cultura jurídica dos cidadãos separadamente de uma transformação da cultura jurídica, não somente dos juízes, mas dos operadores jurídicos no seu conjunto, que são, em definitivo, os seus principais veículos de expansão.

O processo de reelaboração da cultura jurídica da sociedade envolve, portanto, a totalidade das pessoas, sejam, ou não, operadores jurídicos, em uma única dinâmica transformadora. O processo se desvirtuaria caso se optasse por uma análise que permitisse a separação de duas etapas sucessivas: primeiro a transformação da cultura jurídica dos operadores do direito e, somente a partir desse patamar, começaria o caminho de transformação da cultura jurídica dos cidadãos. Ou vice-versa, primeiro a transformação da cultura jurídica dos cidadãos para, a partir desse ponto, encarar a transformação da cultura jurídica dos operadores do direito.

Na primeira das opções nos defrontaríamos com um vanguardismo, ou paternalismo, que se tem mostrado insuficiente e até pernicioso. Na segunda possibilidade, provavelmente se produziriam atritos entre as demandas da sociedade civil já transformada e o corporativismo dos operadores jurídicos.

Somente uma reforma intelectual e moral - no sentido gramsciano - que compreenda a transformação da concepção de mundo jurídico da totalidade dos mem- 
bros da sociedade pode evitar os riscos de processos de transformação parcialmente projetados, nos quais se privilegie um ou outro setor na direção da mudança. O eixo da questão passa pela educação $d a$ e $n a$ cidadania: do cidadão que circunstancialmente desempenha a função de operador jurídico (juiz, advogado, promotor, assistente social, peritos em diversas áreas, etc.); e do cidadão que se encontra circunstancialmente na situação de parte litigante ou litigada em um processo judicial.

O local que aparece como germinal, para a procura de formas institucionais alternativas democratizadoras na questão da administração de justiça, é a cultura jurídica popular reformulada. Onúcleo de bom senso que existe no senso comum de que fala Gramsci (1981) pode ser achado também na cultura jurídica.

Nesta perspectiva, e equacionado o problema da administração de justiça dentro da construção de um projeto de democracia plural e radical, devemos refletir sobre as formas das lutas pela hegemonia. ${ }^{2}$

O problema da crise da administração de justiça não se reduz à questão da reforma do Judiciário, mas à reformulação da organização do poder político no seu conjunto. Por este motivo, trata-se de um assunto imbricado na teoria democrática, entendida esta como a discussão das formas efetivas de participação dos cidadãos no exercício do poder político e das condições materiais e formais necessárias para essa participação.

Ora, a possibilidade de pensar o espaço jurídico-político da administração de justiça como um lugar possível de articulação das lutas democráticas, dentro de um projeto hegemônico de radicalização da democracia, surge somente quando se constitui na cultura jurídica o que Laclau e Mouffe (1987, p. 173) denominam um "exterior discursivo", que abre uma tal possibilidade no imaginário social $^{3}$. Como aconteceu, por exemplo, com a crise política italiana, que abriu a possibilidade histórica para a operação mani pulite nos anos noventa. Ou o processo judiciário instaurado na Espanha contra o ex-ditador chileno Augusto Pinochet, que contribui como exterior discursivo nas polêmicas questões sobre as violações aos direitos humanos durante as ditaduras militares latino-americanas da década de setenta, possibilitando o surgimento de outros processos.

Um elemento desse exterior discursivo hoje está constituído pela insuficiência do contrato social enquanto "metáfora fundadora da racionalidade social e política da modernidade ocidental" (SANTOS, 1998). O contrato social é o discurso que fundamenta a obrigação política moderna. Essa obrigação é complexa e contraditória porque, por um lado, foi estabelecida entre homens hipoteticamente livres e com a finalidade - pelo menos na concepção rousseauniana - de maximizar essa liberdade, mas, por outro lado, a liberdade para ser efetiva deve necessariamente ser exercida dentro da organização política denominada Estado, e conforme com as leis. Neste sentido, o pacto é expressão da tensão permanente entre regulação e emancipação social, entre vontade individual e vontade geral, ou ainda entre interesse particular e bem comum. Através do contrato social se estabelecem as bases da normatividade social que permitem a convivência, favorecendo o livre desenvolvimento das individualidades.

Um dos princípios fundamentais do contrato social é o pressuposto teórico da inexistência de excluídos, já que é condição sine qua non da sociedade política que todos participem da formação das suas normas e se submetam a elas.

A sociedade política surgida do pacto é uma sociedade que se autolegisla, os destinatários das leis são ao mesmo tempo os seus autores. Porém, este pressuposto é uma ficção; na realidade, os únicos legitimados para participar da negociação das cláusulas contratuais são os cidadãos titulares dos direitos políticos, os outros habitantes do território nacional (mulheres, menores, minorias ou maiorias étnicas e outros setores discriminados, que variam segundo as configurações históricas de cada Estado) ficam de fato no estado de natureza, já que carecem dos direitos políticos que lhes permitiriam o acesso às deliberações que estabelecem a normatividade social.

Santos (1998) denomina esses sistemas perversos de exclusão como fascismos sociais, nos quais a lei não é igual para todos, nem todos são iguais perante a lei - segundo a distinção realizada por Cerroni (1993, p. 58). Calamandrei (1998, p. 235) chama a atenção para a mesma perversidade em outro contexto - o fascismo italiano:

Nos tempos do fascismo, no escritório de um advogado conhecido meu, via-se pendurada atrás da escrivaninha, acima de seu assento, uma tabuleta com uma inscrição misteriosa: NÃO É. Quem entrava pela primeira vez naquele escritório ficava perplexo e curioso quanto ao significado daquela inscrição cabalística, mas não ousava pedir explicações, porque eram anos em que se precisava ter cautela com as perguntas. Mas depois, estabelecida a confiança, no se- 
gundo ou terceiro encontro, o interlocutor tomou coragem:

- Desculpe, advogado, perdoe minha ignorância: que significam aquelas duas palavras?

- É uma errata...

- Como assim?

- O senhor já viu nas salas dos tribunais aquele escrito que diz 'a justiça é igual para todos?' É um erro de impressão: onde está escrito 'é', deve-se ler 'NÃO E'.

Dentro da lógica contratualista, esta ficção é necessária e paradoxal. Necessária, porque é fundamental para o Estado garantir a obrigatoriedade política: todos os habitantes do território do Estado encontram-se submetidos às leis; aqueles que não participaram do processo legislativo (direta ou indiretamente, por meio de representantes) não podem invocar essa exclusão para substrairse ao cumprimento das leis. Paradoxal, porque o contrato é ao mesmo tempo uma metáfora de origem e um processo permanentemente renovado que recria a sociedade política através da dinâmica das lutas pela inclusão de alguns setores sociais e contra a exclusão de outros da efetiva participação política. O resultado dessa dinâmica produz a reformulação permanente dos termos do contrato.

Mas em situações de extrema desigualdade social, como na nossa sociedade, os setores excluídos permanecem sempre excluídos, e também a dinâmica do contrato social se converte em uma ficção necessária para manter a vigência dos princípios da obrigação política que fundamentam a legitimidade do Estado.

O outro grande pressuposto teórico do contrato social junto com o da inexistência de excluídos - é a igualdade dos sujeitos contratantes. Quando essa igualdade formal e material inexiste na realidade, a metáfora se desmancha e a realidade da "pura ficção" aparece inelutavelmente. Para manter a metáfora precisamos pensar um novo contrato social, recaracterizando os critérios de inclusão/exclusão como articulações sociais que permitam a inclusão real de todos os setores e de todos os interesses sociais através da dinâmica de uma democracia radical e plural.

Por outro lado, se até agora a figura do contrato social tem servido para legitimar teoricamente a organização política pública denominada Estado, uma nova contratualização deve incluir também na sua dinâmica de discussão/decisão a sociedade civil, num caminho de reunificação da vida social que inclua o público e o privado dentro do mesmo processo. Isto porque, para um projeto de democracia radical e plural, não é suficiente democratizar o Estado sem simultaneamente democratizar o espaço não estatal.

Como Bobbio (1993, p. 42) diz diante desta problemática:

Si se puede hablar hoy de un proceso de democratización, éste consiste no tanto, como erróneamente se dice, en el paso de la democracia representativa a la democracia directa, como en el paso de la democracia politica en sentido estricto a la democracia social, o sea, en la extensión del poder ascendente, que hasta ahora habia ocupado casi exclusivamente el campo de la gran sociedad política [...] al campo de la sociedad civil en sus diversas articulaciones desde la escuela hasta la fábrica.

Essa democratização virá através da criação de novas constelações de lutas democráticas que tornem possíveis amplas deliberações, sob aspectos cada vez mais diferenciados da sociabilidade, inclusive a administração de justiça.

Nesta perspectiva, seria fundamental não somente ampliar os espaços sociais nos quais se delibera democraticamente, mas também as matérias sobre as quais se delibera, quem participa das decisões e sob quais condições reais de existência. A democracia social de Bobbio á apenas um primeiro passo no processo de uma democracia radical.

As lutas democráticas deverão ser lutas por desenhos institucionais alternativos que garantam a igualdade de oportunidade aos diferentes projetos de institucionalidade democrática e que garantam ao mesmo tempo padrões mínimos de inclusão que possibilitem o exercício pleno da cidadania ativa.

Por este ponto de vista, a administração de justiça se apresenta como um espaço a mais de desenvolvimento das relações sociais, com características próprias, mas não por isto isolado da problemática da organização do Estado e da contratualização moderna.

Partindo do pressuposto teórico elaborado por Laclau e Mouffe (1987) - de que não existe nada inelutável ou natural nos diferentes tipos de lutas pela hegemonia -, em cada caso devem ser explicadas historicamente as 
razões da sua emergência e as diferentes formas que as mesmas podem adotar.

A política enquanto criação, reprodução e transformação das relações sociais não pode ser localizada em um determinado lugar do social. O político é o problema da instituição do social, da sua definição e articulação hegemônica no meio dos antagonismos (LACLAUMOUFFE, 1987, p. 171). Então, quais são as condições discursivas exteriores de emergência de uma ação coletiva encaminhada a lutar contra as desigualdades questionando as relações de subordinação?

O caráter de servo ou escravo, por exemplo, não designa por si mesmo situações de antagonismo. $\mathrm{O}$ antagonismo social constitui-se somente quando aparece um discurso exterior que permite a subversão da categoria de servo ou escravo - no exemplo. A possibilidade histórica de surgimento do antagonismo manifesta-se somente a partir do reconhecimento e da declaração dos direitos inerentes a todo ser humano, com a Revolução Francesa. Não existe relação de opressão sem a presença de um "exterior discursivo" a partir do qual o discurso da opressão possa ser interrompido (LACLAU; MOUFFE, 1987, p. 173). Somente quando o discurso democrático se encontrou disponível para articular as diferentes formas de resistência à subordinação é que apareceram as condições de possibilidade de luta contra os diferentes tipos de desigualdade.

Quando os princípios democráticos de igualdade e liberdade se impõem como matriz do imaginário social, produz-se a revolução democrática, chegando ao fim o tipo de ordem social que encontrava o seu fundamento na vontade divina, da qual a sociedade desigual e hierarquicamente constituída era a realização histórica concreta. $\mathrm{O}$ momento fundacional desse novo discurso democrático se encontra na Revolução Francesa: foi então que surgiu pela primeira vez a possibilidade de afirmação do poder soberano do povo.

A Declaração dos Direitos do Homem e do Cidadão proporcionou as condições discursivas que permitiram considerar as diversas formas de desigualdade como ilegítimas e antinaturais, colocando-as como formas de opressão. Dessa primeira manifestação às formas de desigualdade no exercício dos direitos políticos, produz-se um deslocamento, através dos discursos socialistas, para a crítica da desigualdade econômica. Essa discussão conduz ao questionamento de outras formas de subordinação e à reivindicação de novos direitos, abrindo-se um irreversível processo de multiplicação geométrica de novas reivindicações.

A declaração de cada novo direito abre o espaço discursivo para a reivindicação de outros novos direitos e assim sucessivamente, num processo de expansão indefinido e não determinado aprioristicamente. As conseqüências sociais e as possibilidades históricas de novas lutas por novos direitos dependerão sempre das articulações hegemônicas que cada sociedade esteja em condições de produzir, por isto não é possível estabelecer nem ritmos temporais, nem direções determinadas nos processos de transformação social (NOGUEIRA, 2001).

Nesta perspectiva, pode-se explicar por que o problema do acesso à justiça começa a ser reivindicado como um direito somente dentro do discurso do Estado-providência, e também por que a questão da crise do Poder Judiciário começa a ser colocada em termos de reivindicação social apenas recentemente. No primeiro caso, o discurso do Estado-providência possibilita o surgimento das declarações dos denominados direitos sociais, colocando a ênfase na realização efetiva desses direitos declarados. No segundo caso, a crise do Judiciário e a discussão sobre os meios para superá-la (por exemplo, as formas de seleção dos juízes, os controles internos e externos da atividade jurisdicional, etc.), e a exigência de uma ativa participação da sociedade, apresentam-se no bojo da crise do paradigma da contratualização moderna.

Os novos antagonismos - cujo surgimento possibilita a configuração de um novo contexto discursivo - podem apresentar-se em duas variantes fundamentais. A primeria refere-se às relações de subordinação que já existiam e que, em virtude de uma modificação ou alargamento do imaginário democrático, aparecem rearticuladas como relações de opressão. No exemplo do acesso à justiça, sempre se afirmou que os pobres não têm recursos para aceder a um processo judiciário nas mesmas condições que os ricos, mas a reivindicação do acesso à justiça como um direito não aparece antes da década de 1950. Ou seja, antes desse momento, para os setores subalternos não havia a possibilidade de considerar o acesso à justiça como categoria reivindicável, com caráter de direito. Para a segunda variante, o antagonismo pode surgir quando, por exemplo, direitos adquiridos ou relações sociais que não tinham sido constituídas originariamente como relações de subordinação passam a sê-lo, com a modificação das circunstâncias sociais - por exemplo, quando, depois de um rearranjo de forças políticas, uma minoria começa a ser discriminada.

Mas, em todo caso, sempre é o surgimento de um discurso, convertido em senso comum, que abre a possibilidade de que as resistências contra a opressão assumam o caráter de lutas coletivas. Este é o caso dos chamados novos movimentos sociais. Eles são - segundo Laclau (1987, p. 179) - uma extensão da revolução democrática a toda uma nova série de relações sociais.

Podemos também estender esta noção àqueles movimentos que, sem constituir-se como movimentos sociais propriamente ditos, adquirem o significado social de veículos reivindicadores de direitos, como é o caso da atuação das CPIs (Comissões Parlamentares de Inquérito) no Brasil. Também nessas formas institucionais jurídico-políticas se articula o conflito social e se produz a difusão da 
possibilidade de reivindicar direitos referidos a relações sociais cada vez mais diversificadas, numa espécie de sistema de vasos comunicantes, produzindo a transformação do senso comum e preparando assim o surgimento de novos direitos e de novas lutas pelo efetivo exercício desses novos direitos. A expansão da cultura jurídica consiste nesse processo.

Isto foi o que aconteceu com o Estado-providência. Uma vez aceita a responsabilidade do Estado pelo bemestar dos cidadãos, as demandas dirigidas a esse Estado se ampliam. Em conseqüência, a noção de cidadania se modifica, já que se incorporam, ao conceito de cidadão, os direitos sociais. Também são redefinidos, por exemplo, os conceitos de justiça, liberdade, eqüidade e igualdade.

Esta nova concepção da realidade, que chegou a ser hegemônica, inscreve-se no quadro do liberalismo, mas de um liberalismo transformado pela sua articulação com a idéia de democracia. Não se pode compreender a atual expansão do campo do conflito social sem a reformulação da ideologia liberal-democrática, resultante das lutas pela igualdade. É inegável que o discurso liberal-democrático tem sido profundamente modificado por esta ampliação da esfera dos direitos.

Outro elemento característico do contexto discursivo democrático contemporâneo são as novas formas culturais vinculadas à expansão dos meios de comunicação de massas, que têm contribuído para a formação de uma nova cultura e têm produzido transformações consideráveis nas identidades sociais tradicionais. Os efeitos têm sido diversos porque, se por um lado se produz o fenômeno da massificação e uniformização social, por outro lado essa mesma cultura de massa contém elementos de subversão perante as desigualdades, expandindo e até criando novos elementos antagônicos no senso comum. É o caso dos efeitos, em âmbito internacional, causados pela operação mani pulite na Itália, ou pelo processo contra o ditador Pinochet, como já foi mencionado.

No terreno da democracia abre-se um leque de possibilidades, a partir das quais é necessário construir articulações hegemônicas visando ao projeto de democracia plural e radical, já que os diferentes movimentos sociais (em sentido lato) que se produzem no seio da sociedade não têm por si pré-determinada uma potencialidade democratizadora específica - existem, por exemplo, movimentos ecologistas, anticapitalistas, antiindustriais, autoritários, libertários, socialistas, reacionários, etc.

Neste sentido, as formas de articulação dos antagonismos são resultantes de uma luta hegemônica e do projeto hegemônico que essa luta objetiva. As novas lutas sociais por direitos novos, ou pelo efetivo exercício de direitos já reconhecidos, não têm necessariamente um caráter progressista. É um erro pensar que se situam espontaneamente no contexto de projetos políticos de esquerda. $\mathrm{O}$ mais relevante deste ponto de vista é a afirmação da potencialidade germinal desses antagonismos para articularem-se entre si dentro de um projeto hegemônico de democracia plural e radical. Em todos eles se questiona algum ou vários dos critérios de inclusão/exclusão que tipificam o modelo do contrato social moderno. Eis a sua potencialidade, o que lhes outorga sentido, e não o lugar social do qual provêem. Já que não existe lugar privilegiado de implementação da transformação social, tudo dependerá da existência de um projeto político articulador que lute pela hegemonia.

Hoje nos encontramos perante o projeto hegemônico do liberal-conservadorismo, que se articula em torno da definição individualista dos direitos e de uma concepção negativa de liberdade. Produziu-se um rearranjo nos critérios de inclusão/exclusão da formação hegemônica anterior - o Estado de Bem-Estar -, os que ontem foram sujeitos titulares de direitos sociais exigíveis perante o Estado hoje se tornaram - dentro desse discurso - os "parasitas" da seguridade social.

Como vemos, toda transformação social é um processo complexo, sendo o conceito de guerra de posições de Gramsci o que melhor expressa esta idéia, e aquele que nos permite valorizar as potencialidades de transformação da administração de justiça como um ingrediente a mais dentro de um projeto hegemônico de democracia plural e radical.

Mas, para que qualquer tipo de projeto democrático radical e plural seja possível, torna-se necessária, como colocam Laclau e Mouffe (1987, p. 207),

La construcción de un nuevo 'sentido común' que cambie la identidad de los diversos grupos, de modo tal que las demandas de cada grupo se articulen equivalencialmente con las de los otros -en palabras de Marx: 'que el libre desarrollo de cada uno sea la condición para el libre desarrollo de todos los demás'. O sea, que la equivalencia es siempre hegemónica en la medida en que no establece simplemente una 'alianza' entre intereses dados, sino que modifica la propia identidad de las fuerzas intervinientes en dicha alianza.

Toda decisão judicial na resolução de conflitos significa a articulação de diferentes antagonismos sociais, não apenas daquele que está sendo julgado; portanto, toda atuação jurisdicional produz conseqüências em cada um dos espaços sociais em jogo. Toda decisão a respeito de conflitos em uma área do direito - seja trabalhista, civil, comercial, penal, ambiental, etc. - interfere em outros universos de direitos, e sobre os titulares desses direitos, embora não sejam parte formal no litígio. Cada vez que um trabalhador injustamente demitido ganha, através de um processo judicial, o seu direito efetivo à indenização 
declarada na lei, todos as pessoas ganham porque se reafirma o discurso da justiça social trabalhista. Cada vez que uma empresa é multada por agressão ao meio ambiente, todos as pessoas ganham porque se reafirma o discurso da defesa do meio ambiente. Mas é importante levar em conta que o mesmo poderia concluir-se em sentido inverso.

Por este ponto de vis-

ta, a questão dos direitos é redefinida. Em primeiro lugar, são abandonadas a matriz do individualismo possessivo e a idéia da existência de direitos naturais anteriores à sociedade política; os direitos se constroem historicamente porque nunca são individualmente exercidos, eles não existem isoladamente, mas sempre em complexos de relações sociais que os definem.

O exercício dos direitos sempre envolve outros sujeitos - além do titular - que participam da mesma relação social. Neste sentido, todos os direitos, e não apenas os direitos políticos da cidadania tradicional, são direitos democráticos, sempre são exercidos coletivamente e supõem a existência de outros direitos. Ora, a forma específica de constituição desses diversos espaços coletivos, nos quais os direitos surgem e são desenvolvidos, dependerá de cada tipo de relação social (relações de trabalho, relações de produção, relações de família, relações de vizinhança, etc.).

Assim como não existem áreas privilegiadas a priori de surgimento dos antagonismos, tampouco existem discursos sociais que possam ser excluídos a priori da articulação hegemônica, isto porque não existe democracia radicalizada e plural sem a renúncia ao discurso do universal, e portanto à afirmação de um ponto privilegiado de acesso à verdade, acessível somente a um número limitado de sujeitos.

É neste último sentido que colocamos a questão da transformação da cultura jurídica a partir da reelaboração do senso comum jurídico.

Os indivíduos concretos, na sua expressão cotidiana, interpretam, mudam e criam símbolos e significados. Nesse processo é que "acontece", constitui-se e se desenvolve a dinâmica da cultura. Dinâmica que pode ser regressiva ou progressiva segundo tenda a produzir sujeitos sociais autônomos ou sujeitos subalternos.

A administração de justiça, enquanto função voltada fundamentalmente para a aplicação do direito, é veículo social privilegiado na compreensão e reestruturação do sentido do direito e dos direitos. As pessoas adquirem conhecimento dos seus direitos na experiência concreta que deles têm através da sua prática. A administração de jus- tiça é a função do Estado que mais perto dos indivíduos se encontra - comparativamente às outras funções clássicas do Estado: executiva e legislativa -, uma vez que o seu intuito é resolver os conflitos cotidianos das pessoas.

O grau de incidência da atividade dos tribunais na transformação da cultura jurídica é uma questão que deve ser apreciada em cada caso historicamente determinado. Porém, a maioria dos exemplos que cotidianamente se sucedem na prática dos tribunais se refere à expansão de uma cultura jurídica conservadora.

Poderíamos afirmar que a expansão da cultura jurídica democrática contribui para o processo de formação de uma hegemonia dos setores subalternos e que a expansão da cultura jurídica conservadora concorre para a manutenção da hegemonia dos setores dominantes.

Não podemos ser ingenuamente otimistas, como salienta Zaffaroni (1995, p. 182): "Não é tão simples democratizar, posto que as tendências antidemocráticas, ainda quando vejam perdidas suas posições, tratam sempre de se disfarçar sob outra capa, adotando a forma democrática e minando-a a partir do seu meio". Por este motivo, o caminho para qualquer processo de transformação da cultura jurídica passa necessariamente pela democratização interna do Poder Judiciário e pela possibilidade de controle externo da cidadania da atividade jurisdicional. Sem essas mudanças, as vias de articulação da administração de justiça em um projeto hegemônico de democracia plural e radical permanecem limitadas.

Recebido em 14.10.2005.

Aprovado em 15.12.2005.

\section{Referências}

BOBBIO, N. El futuro de la democracia. Buenos Aires: Fondo de Cultura Económica, 1993.

BUTLER, J. et al. Contingencia, hegemonía, universalidad: diálogos contemporáneos en la izquierda. Buenos Aires: Fondo de Cultura Económica, 2003.

CALAMANDREI, P. Eles, os juizes: vistos por um advogado. São Paulo: Martins Fontes, 1998.

CERRONI, U. Política. São Paulo: Brasiliense, 1993.

GRAMSCI, A. Quaderni del Carcere. Edizione Critica dell'Istituto Gramsci a cura di Valentino Guerratana. Torino: Einaudi, 1981. 
LACLAU, E. Misticismo, retórica y política. Buenos Aires: Fondo de Cultura Económica, 2002.

LACLAU, E.; MOUFFE, C. Hegemonía y estrategia socialista. Hacia una radicalización de la democracia. Madrid: siglo XXI, 1987.

NOGUEIRA, M. A. Em defesa da política. São Paulo: Senac, 2001.

NUN, J. Democracia: gobierno del pueblo o gobierno de los políticos? Buenos Aires: Fondo de Cultura Económica, 2000.

SADEK, M. T. (Org.). Acesso à justiça. São Paulo: Fundação Konrad Adenauer, 2001.

SANTOS, Boaventura de Sousa. Os fascismos sociais. Folha de São Paulo, domingo 6 de setembro de 1998.

. (Org.). Democratizar a democracia: os caminhos da democracia participativa. Rio de Janeiro: Civilização Brasileira, 2002.

Reconhecer para libertar: os caminhos do cosmopolitismo multicultural. Rio de Janeiro: Civilização Brasileira, 2003.

SCHERER-WARREN, I.; LÜCHMANN, L. H. H. (Coords.). Dossiê movimentos sociais, participação e democracia. Política e Sociedade. Revista de Sociologia Política, n. 5, out. 2004. Florianópolis: Cidade Futura, 2004.

ZAFFARONI, E. R. Poder Judiciário: crise, acertos e desacertos. São Paulo: Revista dos Tribunais, 1995.

\section{Notas}

1 Exemplos e análises sobre esses novos caminhos para a democracia encontram-se em Santos $(2002 ; 2003)$, em Scherer-Warren e Lüchmann (2004) e especificamente para o tema do acesso à justiça em Sadek (2001).

2 Sobre as discussões em torno ao conceito gramsciano de hegemonia, veja-se Butler et al. (2003).

3 Sobre a constituição das significações políticas e a centralidade dos processos discursivos na construção dos vínculos sociais, indica-se a leitura de Laclau (2002).

\section{María del Carmen Cortizo}

mariac@cse.ufsc.br

Departamento de Serviço Social

Universidade Federal de Santa Catarina

Campus Univ. Prof. João David Ferreira Lima

Florianópolis - Santa Catarina

CEP: 88010-970 